\title{
A Study on Need of Emergency Laparascopic Appendicectomy for Appendiceal Masses
}

\author{
L. Manohar Reddy ${ }^{1}$, Venkata Rama Bai ${ }^{2}$, V. Vijaya Lakshmi ${ }^{3}$ \\ ${ }^{1}$ Assistant Professor, Department of Surgery, Government General Hospital, Ananatapuram, Andhra Pradesh, ${ }^{2}$ Assistant \\ Professor, Department of Surgery, Government General Hospital, Ananatapuram, Andhra Pradesh, ${ }^{3}$ Associate Professor, \\ Department of Surgery, Government General Hospital, Ananatapuram, Andhra Pradesh, India
}

Corresponding author: Dr. V. Vijaya Lakshmi, Associate Professor, Department of Surgery, Government General Hospital, Ananatapuram, Andhra Pradesh, India.

DOI: http://dx.doi.org/10.21276/ijcmsr.2020.5.1.49

How to cite this article: L. Manohar Reddy, Venkata Rama Bai, V. Vijaya Lakshmi. A study on need of emergency laparascopic appendicectomy for appendiceal masses. International Journal of Contemporary Medicine Surgery and Radiology. 2020;5(1):A228-A231.

\section{A B S T R A C T}

Introduction: Appendiceal mass management is a controversial; Immediate appendicectomy is taking a surge over traditional interval appendicectomy. This study was conducted with an aim to know the study various clinical presentations of appendiceal mass and to know the efficacy of surgery among patients presenting with appendiceal mass.

Material and Methods: This study is a prospective, clinical study conducted from June 2017 to September 2018 on 118 patients. After taking history and examination of study population, advised to undergo haematological \& radiological investigations.

Results: $65.2 \%$ had simple mass, $17.7 \%$ showed adhesions, $10.1 \%$ showed perforated appendix and $6.7 \%$ showed loculated abscess. Intra operative difficulties faced were $20.3 \%$ difficulty in localization of appendix, $15.2 \%$ difficulty in adhesiolysis, $5.9 \%$ minor trauma to bowel, $1.6 \%$ minor bleeding and no intestinal perforations happened. Among Post operative complications observed, $16.9 \%$ patients had infection, $15.2 \%$ had delayed bowel recovery, $5.9 \%$ had faecal fistula.

Conclusion: For management of appendicular mass, emergency surgery helps to reduce large financial costs at healthcare centres and reduce economic burden on patients and their families.

Keywords: Appendicular Mass, Surgery, Appendicectomy

\section{INTRODUCTION}

Appendicular mass is an inflammatory mass constituting of localization of inflamed appendix, adjacent viscera and greater omentum. This mass occurs after 3 to 5 days after an attack of acute appendicitis.

This complication occurs in $2-6 \%$ of population presenting with acute appendicitis. ${ }^{1}$ During acute appendicitis inflammation may sometimes fixed as a inflammatory mass (inflammatory phlegmon) or Loculated pus due to persons own defence mechanisms. It can present as a palpable mass few days after the onset of symptoms. ${ }^{2}$

Appendiceal mass management is a controversial; Immediate appendicectomy is taking a surge over traditional interval appendicectomy, however it has some difficulties during operation due to distorted inflamed tissues. So, it is not accepted by few surgeons, still they continue to perform interval appendicectomy. ${ }^{3}$

Interval appendicectomy has resulted in $10-20 \%$ of failures and resulted in complications such as abscess, perforation peritonitis, abscess. ${ }^{4}$ Disadvantages of this traditional approach are need for readmission for another acute episode and increased chance of misdiagnosis which is adding considerable morbidity. ${ }^{5}$
Early surgical intervention of appendiceal mass is a safe method, reduce hospital stay, readmission in hospitals. ${ }^{6}$ Laprascopic invention is a great step among new technologies, it is a safe, feasible method and also reduce economic burden on patients; now a day's large number of surgeons prefer lap appendicectomy for acute appendicitis and appendicular mass.

This study is conducted with an aim to know the study various clinical presentations of appendicular mass and to know the efficacy of surgery among patients presenting with appendicular mass.

\section{MATERIAL AND METHODS}

This study was a prospective, clinical study conducted from June 2017 to September 2018 on 118 patients presenting to Outpatient or emergency departments in the Department of General Surgery in Government Medical College, Anantapuram.

\section{Inclusion Criteria}

Patients of all age groups and both sexes

Presenting with signs and symptoms of Appendicular mass Appendicular mass diagnosed by radiology imaging either USG or CT 


\section{Exclusion criteria}

Patients unfit for surgery

Patients with signs of diffuse peritonitis

Study population clinical history pertaining to age, sex, personal habits, family history, socioeconomic status, presenting complaints was recorded. After taking history, patient is examined for general physical examination and systemic examination.

Patients were advised to undergo preliminary haematological and urine investigations and Confirmation of diagnosis was done by clinical findings and radiological investigations. These patients were followed up by a variable period of time.

\section{STATISTICAL ANALYSIS}

This full data related to study subjects was entered into spread excel sheet. Results were analysed and tabulated. Statistical analyses were expressed as numbers, percentages.

\section{RESULTS}

In the present study, out of 118 patients with appendiceal mass, majority of them were observed in the age group of 2130 years i.e., $49.1 \%$ (58/118), followed by $31-40$ years of age i.e., $22.03 \%(26 / 118),<20$ years of age i.e., $20.3 \%(24 / 118)$ and $>40$ years i.e., $8.4 \%(10 / 118)$. Out of 118 patients 76 (64.4\%) were males and 42 (35.5\%) were females.

All the patients presented with abdominal pain (100\%), followed $87.2 \%$ had anorexia, $72.03 \%$ had nausea/vomiting, 46.6\% had fever, $18.6 \%$ suffered with altered bowel habits and $2.5 \%$ complained of abdominal distension. On clinical assessment $100 \%$ patients had RIF tenderness, $64.4 \%$ showed rebound tenderness and $54.2 \%$ had palpable mass (Table 1 ). $65.2 \%$ had simple mass, $17.7 \%$ showed adhesions, $10.1 \%$ showed perforated appendix and 6.7\% showed loculated abscess (Table 2 \& Fig 1 ).

Intra operative difficulties faced were $20.3 \%$ difficulty in localization of appendix, $15.2 \%$ difficulty in adhesiolysis, $5.9 \%$ minor trauma to bowel, $1.6 \%$ minor bleeding and no intestinal perforations happened (Fig 2).

Among Post operative complications observed, 16.9\% patients had infection, $15.2 \%$ had delayed bowel recovery, $5.9 \%$ had faecal fistula. No failure in treatment noted in these cases (Fig 3).

\section{DISCUSSION}

After acute attack of appendicitis, a tender mass form in the right iliac fossa on $3^{\text {rd }}$ day. This mass is composed of greater omentum, edematous caecal wall, and edematous portions of small intestine. Mass becomes circumscribed on $4^{\text {th }}$ or $5^{\text {th }}$ day, as rigidity passes off its periphery it can be defined clearly Between $5^{\text {th }}$ to $10^{\text {th }}$ day, the swelling becomes larger and can result in abscess collection. Slowly this mass becomes smaller and subsides as the inflammation resolves. ${ }^{\text {? }}$

Treatment of appendicular mass is controversial; however, there are several management options like non surgical treatment, interval appendicectomy, and emergency appendicectomy. Each management option has its own advantage and disadvantage. Successful Non surgical treatment of appendicular mass helpful to patient as there is no need to undergo surgical intervention; but it may hide true diagnosis in few cases and also the underlying diseases such as cancer or crohn's disease may get delayed. ${ }^{8}$ Interval appendicectomy is a traditional method followed to avoid difficulties during operation due to inflammatory tissues; usually operative finding is normal status of appendix. The Disadvantages are need second admission, more complications, more morbidity and cause economic burden to patient. ${ }^{9,10}$ Immediate appendicectomy maybe technically little problematic due to distorted inflammed tissues, adhesions of adjacent viscera and difficulty in closure of damaged tissues; however, it is a safe, feasible, less complications and helps for final diagnosis. ${ }^{11,12}$

In the present study, out of 118 patients with appendicular mass, majority of them were observed in the age group of 2130 years i.e., $49.1 \%(58 / 118)$. Out of 118 patients $76(64.4 \%)$ were males and $42(35.5 \%)$ were females. Bahram MA et $\mathrm{al}^{13}$ did a 4 year period randomized study, reported the mean age patient as $24 \pm 8.76$. Bulent Kaya et $\mathrm{al}^{14}$ observed the mean age of patient is $37.23 \pm 15.60$ and male predominance observed (53.2\%). Al- Samarrai et $\mathrm{al}^{15}$ documented $68 \%$ of males had appendicular mass.

$65.2 \%$ had simple mass, $17.7 \%$ showed adhesions, $10.1 \%$ showed perforated appendix and $6.7 \%$ showed loculated

\begin{tabular}{|l|c|c|l|c|c|}
\hline Symptoms & No. of patients & Percentage & Signs & No. of patients & Percentage \\
\hline Abdominal Pain & 118 & $100 \%$ & RIF tenderness & 118 & 100 \\
\hline Nausea/Vomiting & 85 & $72.03 \%$ & Rebound tenderness & 76 & 64.4 \\
\hline Fever & 55 & $46.6 \%$ & Palpable mass & 64 & 54.2 \\
\hline Anorexia & 103 & $87.2 \%$ & & & \\
\hline Altered bowel habits & 22 & $18.6 \%$ & & & \\
\hline Abdominal distension & 3 & $2.5 \%$ & & \\
\hline \multicolumn{7}{|l|}{ Table-1: Clinical features of patients with appendicular mass } \\
\hline
\end{tabular}

\begin{tabular}{|l|c|c|}
\hline Findings & No. of patients & Percentage \\
\hline Simple mass & 77 & $65.2 \%$ \\
\hline Loculated abscess & 8 & $6.7 \%$ \\
\hline Adhesions & 21 & $17.7 \%$ \\
\hline Perforated appendix & 12 & $10.1 \%$ \\
\hline \multicolumn{2}{|c|}{} \\
\hline
\end{tabular}


abscess as per this study. In similar to this study, Malik Arshad et $\mathrm{a}^{16}$ observed $72.7 \%$ had simple mass, $9.1 \%$ perforated appendix, $8 \%$ abscess, $5.7 \%$ adhesions. Shindholimath VV et $\mathrm{al}^{17}$ noted $36.8 \%$ of perforated appendix, $31.5 \%$ appendicular abscess, $26.3 \%$ gangrenous appendix and 1 case of Loculated pus $(5.2 \%)$.Whereas Samuel $\mathrm{M}$ et $\mathrm{al}^{18}$ reported higher percentage of cases had abscess i.e., $79.2 \%$ and adhesions in 81.3\%.

Among Post operative complications observed, 16.9\% patients had infection, $15.2 \%$ had delayed bowel recovery, $5.9 \%$ had faecal fistula. No failure in treatment noted in these cases in this study. Malik Arshad et $\mathrm{al}^{16}$ reported 21.6\% post operative complications and Samuel $\mathrm{M}$ et a $\mathrm{al}^{18}$ reported no post operative complications. Zaza Demetrashvili et al ${ }^{19}$ documented out of 48 patients with appendiceal mass and

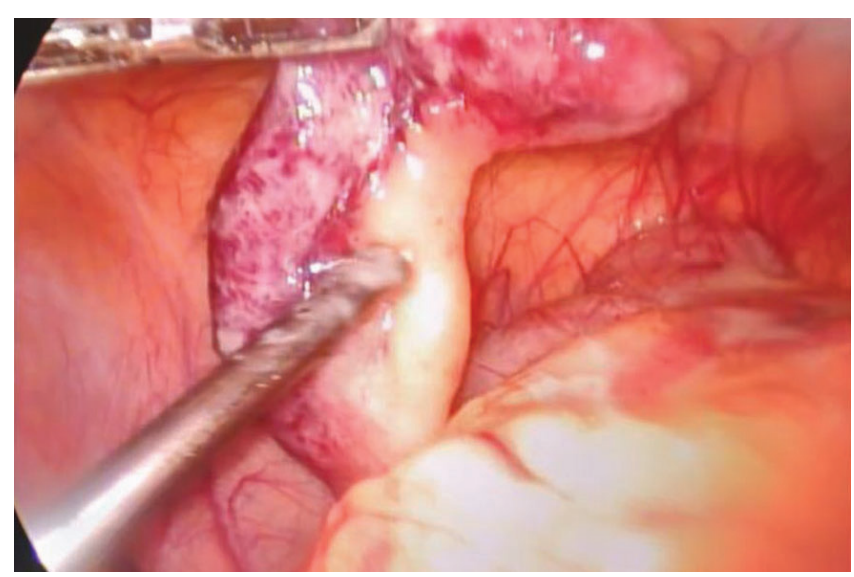

Figure-1: Showing Inflammed appendix with adhesions

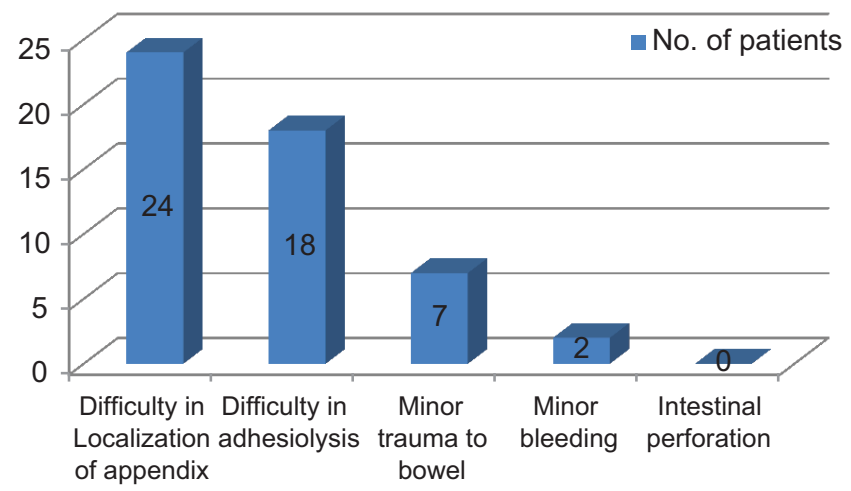

Figure-2: Showing intra operative difficulties

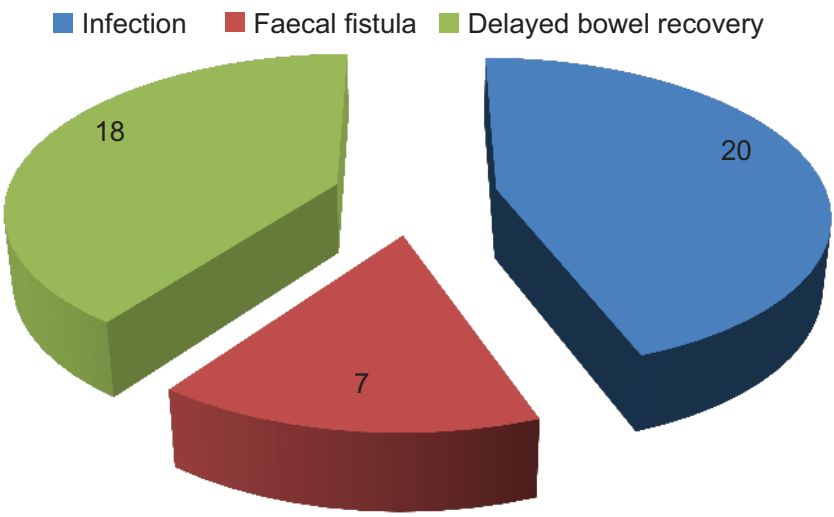

Figure-3: Showing postoperative complications incidence abscess only 4 patients had post operative complication due to infection.

Chin et $\mathrm{al}^{20}$ mentioned that in their study they observed morbidity rate of $15.7 \%$ and they found laparoscopic appendicectomy is a safe and feasible study. Richards et $\mathrm{al}^{21}$ did a study on perforated appendicitis, observed as laparoscopic study is a safe method with fewer complications, reduced hospital stay and lower hospital cost than open surgery. Shindholimath VV et al ${ }^{17}$ did a study on laparoscopic study, stated that all appendiceal mass patients were treated successfully by laparascopic surgery. In contrast to our study Valla et $\mathrm{al}^{22}$ recommended open appendicectomy for appendiceal masses.

Bhumika Jayantilal Patel et a ${ }^{23}$ stated that among interval appendicectomy patients average length of hospital stay was 11 days whereas in emergency surgery cases hospital stay was 4 days. Poor patient compliance, failure of treatment, residual collections/abscess, readmission and failure to locate appendix on delayed appendicectomy were problems faced in Interval appendicectomy.

Senapathi PS et al ${ }^{24}$ opted laparascopic appendicectomy for 10 patients with appendicular mass and 50 patients with appendicitis. They didn't found any statistical difference in terms of operative time (median [interquartile range]: 45 [36-60] vs $40[25-50] \mathrm{min}, \mathrm{p}=0.085)$ and postoperative hospital stay (median [interquartile range]: 2 [1-2] vs [1-2] days, $\mathrm{p}=0.1$.

Goh BK et $\mathrm{al}^{25}$ studied on 88 patients performed LA for 22 patients with appendiceal mass, 36 patients with simple appendicitis, 23 patients with other complicated appendicitis and 7 patients with normal appendix. Patients who underwent early LA for an appendiceal mass had a statistically significant $(\mathrm{P}<.05)$ with regards to longer operating time (median, 103 minutes; interquartile range, 90-151 minutes, vs median, 87 minutes; interquartile range, 71-112 minutes), prolonged time to ambulation (median, 2.0 days; interquartile range, 2-2.5 days, vs median, 1.0 days; interquartile, 1-2 days), increased time to resumption of diet (median, 4 days; interquartile, 3-5 days, vs median, 2 days; interquartile, 2-3 days), and longer postoperative stay (median, 6.0 days; interquartile, 5.5-6.5 days, vs median, 4.0 days; interquartile, 3-5.5 days) compared with patients presenting with appendicitis without mass formation.

Zaza Demetrashvili et $\mathrm{al}^{19}$ did a comparative study of emergency appendicectomy and interval appendicectomy on patients with appendicular mass and abscess. They have observed there is no statistical difference of both groups in terms of operation time without colonic resections, postoperative complications and the post operative hospitalization period. The only parameter found statistically reliable between two groups was operation time with colonic resections $(\mathrm{P}=0.04)$.

Garg $\mathrm{P}$ et al ${ }^{26}$ stated that there is chance of mismanagement conservatively, may miss diagnosis of certain conditions like intussusceptions and carcinoma ceacum.

Most of the studies concluded that immediate appendicectomy and interval appendicectomy have shown the same results, statistically there is no much difference. Selection of procedure depends on clinical situation, 
investigation related. In each particular case therapeutic approach is different.

\section{CONCLUSION}

For management of appendicular mass, emergency surgery helps to reduce large financial costs at healthcare centres and reduce economic burden on patients and their families. Emergency surgery is a safe, feasible method. CT scan is a useful method to diagnose this condition. Immediate appendicectomy helps to ruel out other diagnoses, alleviates needs for readmission, time saving, shortens hospital stay.

\section{REFERENCES}

1. Jordan JS, Kovalcik PJ, Schwab CW: Appendicitis with a palpable mass. Ann Surg; 1981; 193(5):227-9.

2. Yamini D, Vargas H, Bongard F, Klein S, Stamos MJ. Perforated appendicitis: is it truly a surgical urgency? Am Surg. 1998;64(2):970-975.

3. Erdogan D, Karaman I, Narci A, Karaman A, Cavuşoğlu YH, Aslan MK, et al. Comparison of two methods for the management of appendicular mass in children. PediatrSurg Int. 2005; 21(2):81-3.

4. Kaya B, Sana B, Eriş C, Kutaniş R. Immediate appendectomy for appendiceal mass. Ulus Travma Acil Cerrahi Derg 2012;18(6):71-4

5. Garg P, Dass BK, Bansal AR, Chitkara N. Comparative evaluation of conservative management versus early surgical intervention in appendiceal mass - a clinical study. J Indian Med Assoc 1997;95(1):179-80, 196.

6. Shindholimath VV, Thinakaran K, Rao TN, Veerappa YV. Laparoscopic management of appendicular mass. J Minim Access Surg 2011;7(4):136-40.

7. Karaca I, Altintoprak Z, Karkiner A, Temir G, Mir E: The management of appendiceal mass in children, is interval appendicectomy necessary? Surg Today, 2001; 31(8):675-7.

8. Andersson RE, Petzold MG. Nonsurgical treatment of appendiceal abscess or phlegmon: a systematic review and meta-analysis. Ann Surg. 2007;246(1):741-748.

9. Verwaal VJ, Wobbes T, Goris RJA. Is there still a place for interval appendectomy? Dig Surg. 1993;10(5):285288

10. Corfield L. Interval appendicectomy after appendiceal mass or abscess in adults: what is "best practice"? Surg Today. 2007;37(3):1-4

11. Yamini D, Vargas H, Bongard F, Klein S, Stamos MJ. Perforated appendicitis: is it truly a surgical urgency? Am Surg. 1998;64:970-975.

12. Tingstedt B, Bexe-Lindskog E, Ekelund M, Andersson R. Management of appendiceal masses. Eur J Surg. 2002;168(3):579-582.

13. Bahram MA. Evaluation of early surgical management of complicated appendicitis by appendicular mass. Int J Surg. 2011; 9(1):101-3.

14. Bulent Kaya, Baris Sana, Cengiz Eris, Riza Kutanis. Immediate appendectomy for appendiceal mass. Ulus Travma Acil Cerrahi Derg 2012; 18 (1):71-74.

15. Al - Samarrai A. Surgery for appendicular mass. Saudi J Gastroenterol. 1995;1:43-6.

16. Malik Arshad, Laghari A. Aziz, MallahQasim, K. AltafHussainTalpur Early appendicectomy in appendicular mass - a Liaquat university hospital experience J Ayub Med Coll Abbottabad 2008;20(1).

17. Shindolimath VV, Thinakaran K, Narayana Rao $\mathrm{T}$ and Veerappa YV. Laparascopic management of appendicular mass. J Minim Access Surg. 2011; 7(2): 136-140.

18. Samuel M, Hosie G, Holmes K. Prospective evaluation of nonsurgical versus surgical management of appendiceal mass. J Pediatr Surg. 2002;37(6):882-6.

19. Zaza Demetrashvili, Giorgi Kenchadze, Irakli Pipia, Eka Ekaladze and George Kamkamidze. Management of Appendiceal Mass and Abscess - An 11 year experience. Int Surg. 2015;100(6):1021-1025.

20. Chin CY,ShilC, Chun YC.Laparoscopic appendectomy for ruptured appendicitis. Surg Laparosc Endosc. 1999;3(2):271-5.

21. Richards KF, Fisher KS, Flores JH, Christensen BJ. Laparoscopic appendectomy: Comparison with open appendectomy in 720 cases. Surg Laparosc Endosc. 1996;6(1):205-9.

22. Valla JS, Steyaert H, Alain LJ. Management of appendicular peritonitis in children: Traditional surgery vs. laparoscopy. Retrospective comparative study of pediatric video surgery group. Int J. Pediatr Surg Sci. 1996;10(4):13-6.

23. Bhumika Jayantilal Patel, Kalpesh Himatlal Patel. A comparative study of appendicular lump management. 2015;2(2).

24. Senapathi PS, Bhattacharya D, Amori BJ. Early laparoscopic appendectomy for appendicular mass. Surg Endosc. 2002; 16(12):1783-5.

25. Goh BK, Chui CH, Yap TL, Low Y, Lama TK, Alkouder G, Prasad S, Jacobsen AS. Is early laparoscopic appendectomy feasible in children with acute appendicitis presenting with an appendiceal mass? A prospective study. J Pediatr Surg. 2005;40(7):1134-7.

26. Garg P, Dass BK, Bansal AR, Chitkara N. Comparative evaluation of conservative management versus early surgical intervention in appendicular mass-a clinical study. Indian Med Assoc.1997; 95(6):179-80.

Source of Support: Nil; Conflict of Interest: None

Submitted: 31-12-2019; Accepted: 16-02-2020; Published online: 20-03-2020 